\title{
Prospects of Silk Sericin Membranes Fabricated with Tyrosinase ${ }^{\star}$
}

\author{
Muying Yang ${ }^{\mathrm{a}}$, Xinyue $\mathrm{Li}^{\mathrm{a}}$, Shenzhou $\mathrm{Lu}^{\mathrm{a}}$ \\ Guoqiang Chen ${ }^{\mathrm{a}}$, Tieling Xing ${ }^{\mathrm{a}, \mathrm{b}, *}$ \\ ${ }^{a}$ College of Textile and Clothing Engineering, Soochow University, Suzhou 215123, China \\ ${ }^{\mathrm{b}}$ Xinyuan Cocoon and Silk Group Co., Ltd, Haian 226600, China
}

\begin{abstract}
Biological enzyme is a kind of substance, which can catalyze specific reaction. In our work, sericin membranes are prepared under the catalysis of tyrosinase, which promoting protein molecules crosslinking through tape casting method. Taking the water solubility of sericin membranes as the evaluation index, the optimal preparation conditions are determined as follows: the dosage of tyrosinase $1000 \mathrm{U} / \mathrm{g}$, the reaction temperature $45{ }^{\circ} \mathrm{C}$, for $90 \mathrm{~min}, 2 \%$ glycerol and drying temperature at $45{ }^{\circ} \mathrm{C}$. The results of infrared spectra indicate that the structure of amide $\mathrm{I}$ is changed in crosslinked sericin membranes. The XPS results indicate the $\mathrm{O}$ atom content is increased in crosslinked sericin membrane. This verifies the crosslinking of sericin protein by tyrosinase.
\end{abstract}

Keywords: Tyrosinase; Crosslinking; Sericin Membranes; Water Solubility

\section{Introduction}

The last 20 years have seen an explosion in the level of research devoted to the development of new biodegradable materials, essentially due to the desire to protect the environment [1]. As a renewable resource, protein is abundant in nature, with non toxicity, non pollution, biodegradability and no stimulation, and has been a research hotspot in materials fields for a long time. As textile materials, the application of protein fibers such as silk and wool have been paid much attention in recent years. The protein collagen and gelatin were first studied as membranes materials. Numerous studies have investigated the effect of seeds plant protein on the preparation of edible films and food wrapping films. Orliac et al. [1] succeed to prepare sunflower protein membranes and also studied the effects of glycerol, ethylene glycol, diethylene glycol, triethylene glycol and propylene glycol on the thermoplastic potential of a sunflower protein isolate. Mengqin

${ }^{\star}$ Project supported by National Natural Science Foundation of China (Nos. 51203107, 51373114); PAPD (A Project Funded by the Priority Academic Program Development of Jiangsu Higher Education Institutions) and Qing Lan Project.

${ }^{*}$ Corresponding author.

Email address: xingtieling@suda.edu.cn (Tieling Xing). 
L. et al. [2] prepared edible wheat gluten films with good comprehensive properties. Akturk et al. [3] studied the wound dressing membranes of sericin and collagen, which were stable in 4 weeks. Weijing L. et al. [4] studied the effect of different sugars grafting on physical properties of peanut protein films. In addition to those above seeds plant protein membranes, some other variety of protein membrane materials are also widely used in the cosmetics, food products, and medications.

Silk protein, including silk fibroin and sericin protein, is one of the earliest natural proteins used by people. Sericin, a kind of water-soluble globular protein, constitutes about $25 \%$ of silk protein [5]. Sericin is made of 18 amino acids such as serine, aspartic acid and tyrosinase. In the past, sericin was mostly discharged with the silk processing waste water. Recently, the researchers realized that the sericin protein represents a significant economic and social benefit if it can be recovered and recycled [5]. Consequently, sericin is used in the cosmetics, health care products, and medical fields. The sericin protein is easy to form membranes. The sericin membrane is usually used as cell culture medium and wound covering materials. However, the sericin membrane is thin and fragile. Some crosslinking agents are used to prepare crosslinking membrane, such as polyvinyl alcohol and polyethylene glycol. Ruijuan X. et al. [6] prepared sericin films with polyethylene glycol diglycidyl ether (PEG-DE) as crosslinking agent. The films showed good flexibility and high elongation at break. Su W. et al. [7] prepared blend hydrogel membranes with polyvinyl alcohol and sericin. On the positive side, chemical modification helps to form crosslinking between sericin and thereby enhance the properties of membranes. However, chemical modification may affect the biocompatibility of sericin protein and cause many toxicity problems.

On people advocating healthy and environmental materials, the development of green crosslinking agents such as enzymes become a new research hotspot. Enzyme as a biocatalyst with high substrate specificity, catalytic efficiency, biodegradability and non-toxicity, can catalyze the formation of inter- and/or intra-molecular crosslinks in sericin protein. Recently, tyrosinase was used as crosslinking agents in the preparation of sericin protein $[8,9]$, but the research on the properties of the sericin membranes was little.

Tyrosinases (EC 1.14.18.1) are copper-containing enzymes having a binuclear copper catalytic site [10]. They have been isolated from higher animals, microorganisms (bacteria, fungi), plants, and insects [11]. Tyrosinases are capable of oxidizing polyphenols to quinones. Thus, they are the rate-limiting enzyme required for melanin production [12]. The enzymatic reaction mechanism of tyrosinase involves first the formation of coordination bonds between $\mathrm{Cu}^{2+}$ and the amino residue of enzyme protein which become an active site with a specific three-dimensional structure. The substrate, contains o-quinone group, is capable to react with the active site due to proximity effects and orientation arrange. As a consequence, a composite product of enzyme and substrate is formed through hydrogen bonds between hydroxy of $o$-quinone and the residue of polypeptides. However, the composite product is unstable. The conformation of polypeptide become warped and the hydrogen bonds fracture in a short time. Then the composite product finally becomes $o$-quinone, which continues to occur series secondary oxidation reactions spontaneously. By dehydrogenation, the conformation of tyrosinase rotates and then restores the previous native conformation catalytic ability [13].

Our research was based on the mechanism in Fig. 1. Sericin was used as the substrate which contained phenolic hydroxyl. The tyrosinase catalyzed the sericin protein by two ways: one is oxidizing monohydric phenol of protein to diphenol (o-phenol, OPP), the other one is generating 
o-benzoquinone by the oxidation of tyrosinase. Both ways need the presence of oxygen molecules. When $o$-phenol changed into $o$-benzoquinone, the $o$-benzoquinone further response with the amino group of sericin protein through Michael addition reaction or Schiff-base reaction. Accordingly, the crosslinking between sericin proteins was formed.

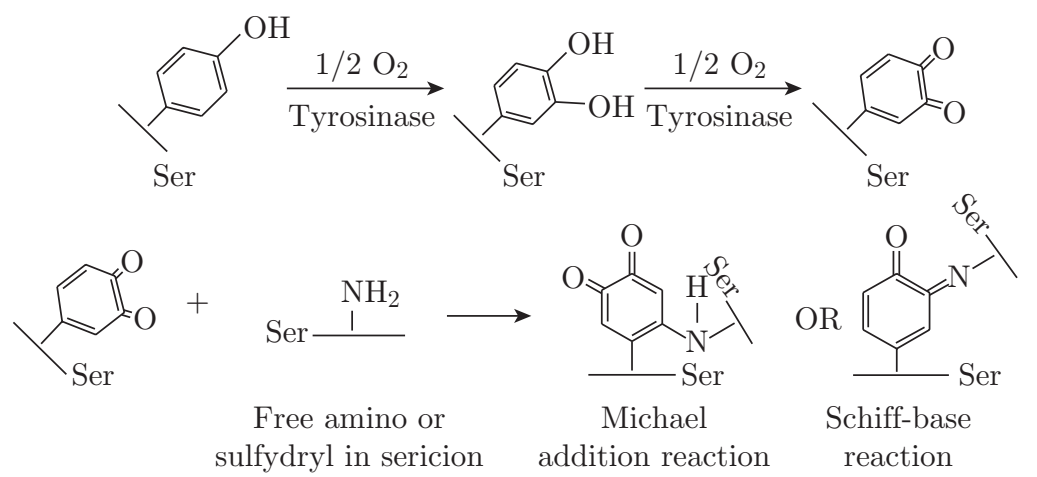

Fig. 1: Schematic of sericin membranes fabricated with tyrosinase

In this study, the tyrosinase was used to catalyze the crosslinking between sericin membranes. Chemical modification may affect the biocompatibility of sericin protein while enzyme is a biocatalyst with biodegradability, which can catalyze the formation of sericin membranes environmentally friendly. Furthermore, the properties of sericin membrane were investigated systematically.

\section{Materials and Methods}

\subsection{The Preparation of Sericin Membranes}

The cocoon shells (supplied by Jiangsu Xinyuan Cocoon Silk Co. LTD, China) were cut into small pieces $(1 \mathrm{~cm} \times 1 \mathrm{~cm})$. The cut pieces were thoroughly washed with water repeatedly. The sericin solution was obtained by boiling in the deionized water for $40 \mathrm{~min}$. The liquor ratio was 14:1. The concentration was tested according to the total solid content [6].

Sericin solution prepared before was mixed with different dosages of tyrosinase (T3824-50KU, purchased from Sigma Chemical Co., USA) to react for a certain period of time. The sericin protein membranes were prepared by tape casting method and then the properties of the sericin membranes were tested. The dosage of tyrosinase $(\mathrm{U} / \mathrm{g})$ was calculated based on sericin protein (g). The dosage of glycerol (\%) was on the basis of the percentage of sericin protein. One unit $(\mathrm{U})$ is defined as the amount of tyrosinase which causes an increase in $\mathrm{A}_{280 \mathrm{~nm}}$ of 0.001 per minute in the conditions of the test [14].

The optimal preparation condition of sericin membranes were investigated based on the dosage of tyrosinase, reaction temperature, time, drying temperature of the membranes, with or without glycerol.

\subsection{Water Solubility}

(1) The standard curve of sericin solution by ultraviolet spectrophotometer 
A certain concentration of silk sericin protein was used to find the maximum absorption wavelength by using spectral scan (The wave ranges from 200 to $400 \mathrm{~nm}$ ). Different concentrations of sericin solutions were prepared in order to measure the absorbance in the maximum absorption wavelength (275 $\mathrm{nm}$ in our work) by ultraviolet spectrophotometer. The result was dealt with regression equation to get the UV absorbance $K_{a}$ of sericin $(K)$ [15].

(2) The measurement of moisture content

The sericin membrane was first conditioned at $25{ }^{\circ} \mathrm{C}$ and $65 \%$ relative humidity for $24 \mathrm{~h}$ before weighting. The sample was cut into three parts with the same weight $w_{1}(\mathrm{~g})$. The samples were placed in oven $\left(105^{\circ} \mathrm{C}\right)$ to obtain constant weight $w_{2}(\mathrm{~g})$. The moisture content $\omega$ was calculated using Eq. (1):

$$
\omega=\frac{w_{1}-w_{2}}{w_{1}} \times 100 \%
$$

(3) The measurement of water solubility

The sericin membrane was conditioned at room temperature for $24 \mathrm{~h}$ and then weighted $w_{1}(\mathrm{~g})$ sample in the triangular flask. Afterwards, the triangular flask was placed in water-bathing constant temperature vibrator preheating for $30 \mathrm{~min}$. The sericin membrane and water weight ratio was 1:100. After $24 \mathrm{~h}$ of vibrating at $37^{\circ} \mathrm{C}$, the absorbance of the above sericin membrane was detected at $275 \mathrm{~nm}$. Finally, the water solubility of sericin protein was calculated using Eq. (2):

$$
C=\frac{K A V}{w_{1} \times(1-\omega)}
$$

where $C$ is the water solubility of sericin protein (\%); $K$ is UV absorbance $K_{a}$ of sericin $(\mathrm{g} / \mathrm{mL})$; $A$ is the absorbance; $V$ is the volume of the solution $(\mathrm{mL}) ; w_{1}$ is the mass of sample $(\mathrm{g}) ; \omega$ is the moisture content. The UV absorbance $K a$ of sericin was determined by Lambert-Beer's law.

\section{$2.3 \quad$ FT-IR Spectroscopy}

Fourier transform infrared spectroscopy was performed with a Nicolette 5700 FT-IR spectrometer (Nicolet Co., USA). The crosslinking sericin membranes were cut into micro-particles with radius about $4-5 \mu \mathrm{m}$ and then analyzed by FT-IR spectroscopy. The spectra were recorded over the range $4000-500 \mathrm{~cm}^{-1}$, with a resolution of $4 \mathrm{~cm}^{-1}$.

\subsection{XPS}

The O1s, C1s, N1s content of the crosslinking sericin membranes were analyzed by X-ray photoelectron spectroscopy (Axis Ultra HAS, KRATOS Co., Jap).

\section{Results and Discussion}

\subsection{The Measurement of UV Absorbance $K_{a}$}

A low concentration of sericin protein was used to find the maximum absorption wavelength. The maximum absorption wavelength in this experiment was $275 \mathrm{~nm}$. The sericin solution of different 
concentrations, $0,50,100,150,200,250,300,350,400,450,500 \mu \mathrm{g} / \mathrm{ml}$, were prepared to test the absorbance under the maximum absorption wavelength.

The UV absorbance curve was shown in Fig. 2 as a function of sericin concentration. Using linear regression to linear fit the curve and a linear fitting straight line were drawn. The slope of the curve was 0.0007 and the UV absorbance $K_{a}$ of sericin was $1.43 \times 10^{-3}$. Finally, the water solubility of sericin membrane was calculated using Eq. (2).

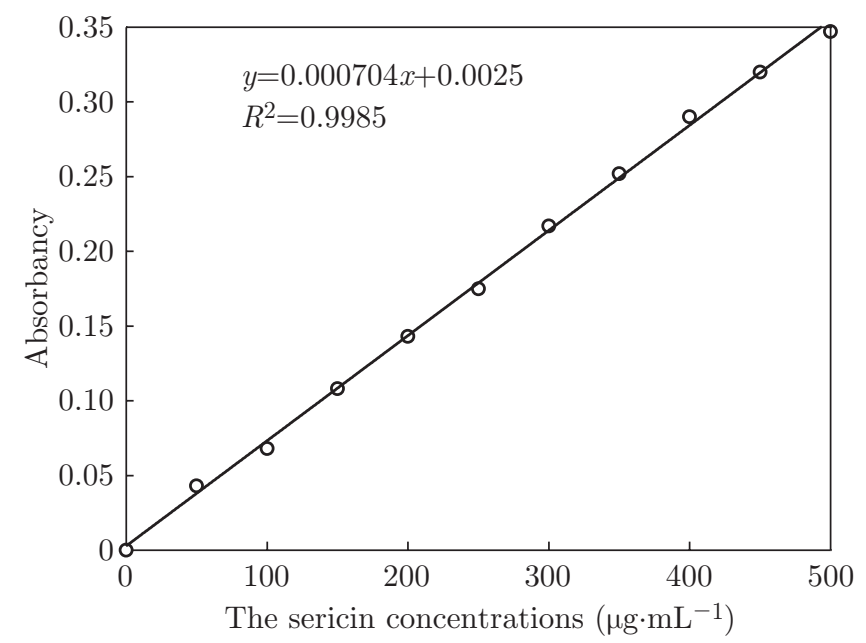

Fig. 2: The absorbance of different concentrations of sericin under the maximum absorption wavelength

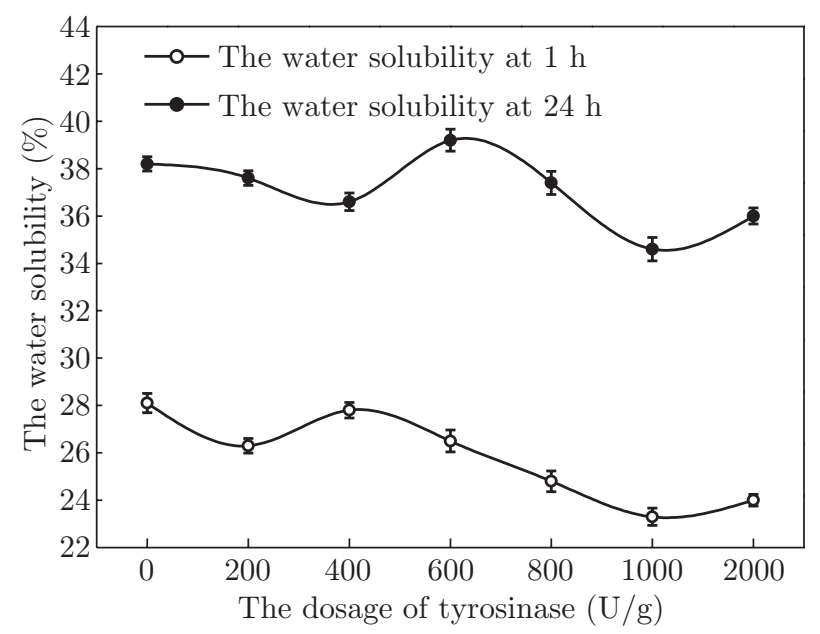

Fig. 3: The effect of tyrosinase dosage on the water solubility of sericin membranes (Reaction temperature $45^{\circ} \mathrm{C}$, reaction time $120 \mathrm{~min}$, drying temperature $40{ }^{\circ} \mathrm{C}$ )

\subsection{The Effect of Tyrosinase Dosage on the Water Solubility of Sericin Membranes}

In order to analyze the effect of tyrosinase, the sericin protein membranes were prepared with different dosage of tyrosinase. The water solubility at $1 \mathrm{~h}$ and $24 \mathrm{~h}$ of each membrane was tested. The results are presented in Fig. 3. The water solubility of sericin membranes fluctuated with the dosage of tyrosinase (Fig. 3). Moreover, the water solubility of sericin membranes was improved 
after adding tyrosinase and the water solubility at $1 \mathrm{~h}$ was lower than that at $24 \mathrm{~h}$. Compared with the two sets of data, the water solubility was relatively low when the dosage of tyrosinase was $1000 \mathrm{U} / \mathrm{g}$. As a consequence, the optimal dosage of tyrosinase was determined as $1000 \mathrm{U} / \mathrm{g}$.

This is because sericin is made of 18 amino acids such as serine, aspartic acid and tyrosine [8]. Hence, there exist a large proportion of tyrosinase residues in sericin. In the presence of $\mathrm{O}_{2}$, tyrosinase can catalyze the oxidation of free tyrosinase residues to produce o-quinone or other more complex products. In other words, the sericin protein was oxidized by tyrosinase through nucleophilic reaction and the crosslinking between sericin macromolecular chains were gradually formed. The molecular interactions were reinforced. The small molecular chain segments gathered towards the macromolecular chain segments to reach a certain degree of crosslinking. Compared with membranes without the catalysis of tyrosinase, the water solubility of the crosslinking sericin membranes was relatively low.

\subsection{The Effect of Reaction Temperature on the Water Solubility of Sericin Membranes}

Fig. 4 shows the effect of temperature on the water solubility of sericin membranes. The temperature had less influence on the water solubility at $1 \mathrm{~h}$ whereas making a big difference to the water solubility at $24 \mathrm{~h}$. When the temperature reached $45^{\circ} \mathrm{C}$, the water solubility was the was obviously the lowest.

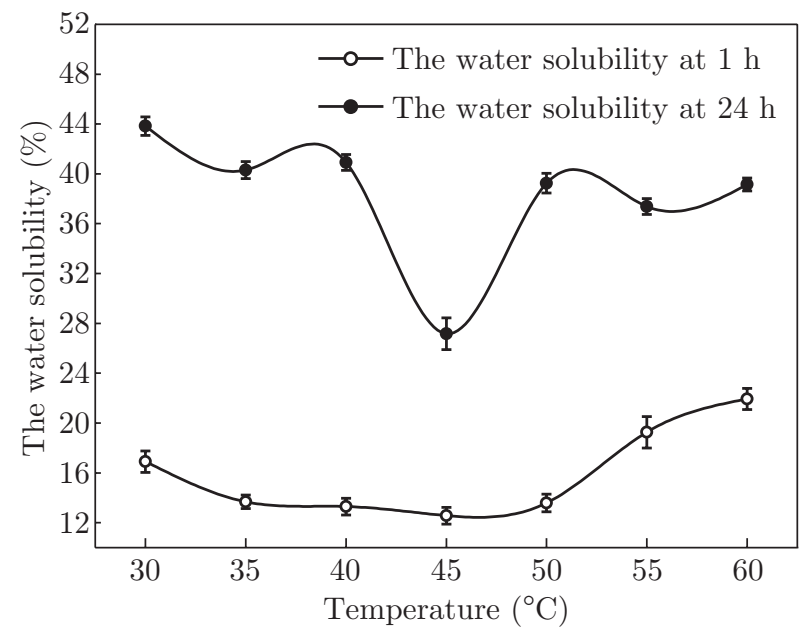

Fig. 4: Effect of temperature on the water solubility of sericin membranes (Tyrosinase $1000 \mathrm{U} / \mathrm{g}$, reaction time 90 min, drying temperature $40{ }^{\circ} \mathrm{C}$ )

Enzymes are of proteins which denaturize at high temperature [15] and enzyme has its optimal reaction temperature at which it plays the maximum catalysis efficiency. At low reaction temperature, the rate of enzymatic reaction was relatively low, resulting the catalysis efficiency of tyrosinase was also low and the reaction time was extended. If the temperature was raised beyond the optimal one, tyrosinase might be deactivated and the activity declined abruptly. Consequently, the reaction temperature has a distinct affect on the catalysis of the sericin crosslinking and water solubility for $24 \mathrm{~h}$ of water solubility of sericin membrane. Based on the above analysis, the optimal temperature was chosen as $45^{\circ} \mathrm{C}$. 


\subsection{The Effect of Reaction Time on the Water Solubility of Sericin Membranes}

The effect of time on the water solubility of sericin membranes was shown in Fig. 5. As reaction time was prolonged, the water solubility of sericin membranes at $1 \mathrm{~h}$ decreased significantly while $24 \mathrm{~h}$ presented a fluctuation.

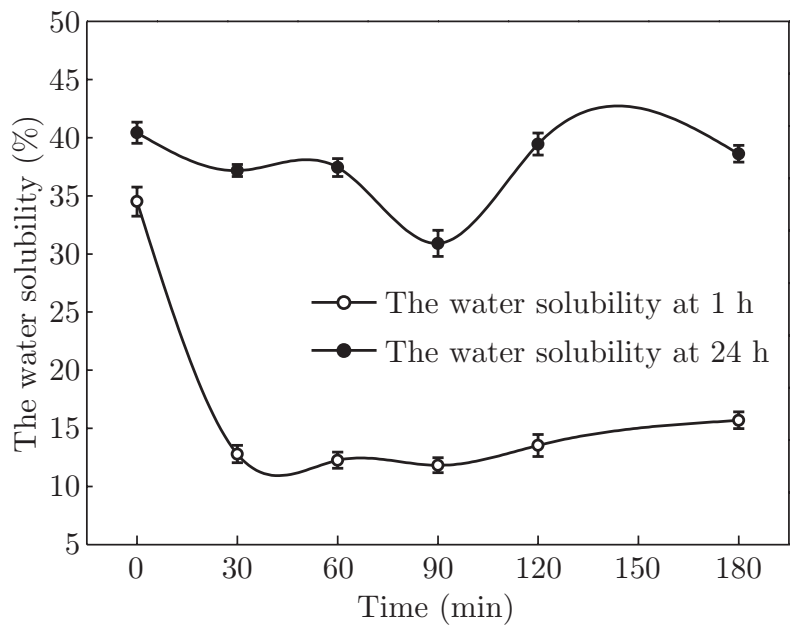

Fig. 5: The effect of time on the water solubility of sericin membranes (Tyrosinase $1000 \mathrm{U} / \mathrm{g}$, reaction temperature $45^{\circ} \mathrm{C}$, drying temperature $40{ }^{\circ} \mathrm{C}$ )

The water solubility of both $1 \mathrm{~h}$ and $24 \mathrm{~h}$ reached a low value when the reaction time was 90 min. The tyrosinase residues in the sericin protein were catalyzed by tyrosinase. Because the number of these reaction groups in sericin were limited, the water solubility of membranes cannot be improved even prolonging the reaction time. Therefore, the optimal time was chosen as 90 min.

\subsection{The Effect of Drying Temperature on the Water Solubility of Sericin Membranes}

The sericin protein used in our work was degummed directly from cocoons without degradation process so that the molecular weight of sericin protein was very large. When the sericin solution was exposed to the air to volatilize the water spontaneously, the solution was easy to gelate. It was unfavorable for film forming at the end of the reaction between sericin protein and tyrosinase. Moreover, the gel prevented the volatilization of the water and then the film forming speed was slowed down. Therefore, the sericin membrane fabrication was performed at certain temperature after the enzymatic reaction in our experiment.

Fig. 6 shows the effect of drying temperature on the water solubility of sericin membranes. The water solubility of sericin membranes changes with the drying temperature. With the increasing of drying temperature, the water solubility of membranes at $1 \mathrm{~h}$ was increased. The curve of water solubility at $24 \mathrm{~h}$ showed volatility and reached the lowest water solubility at $40{ }^{\circ} \mathrm{C}$. The effect of drying temperature on the water solubility of sericin membranes was little. When combined with other factors, the optimal drying temperature was $40^{\circ} \mathrm{C}$. 


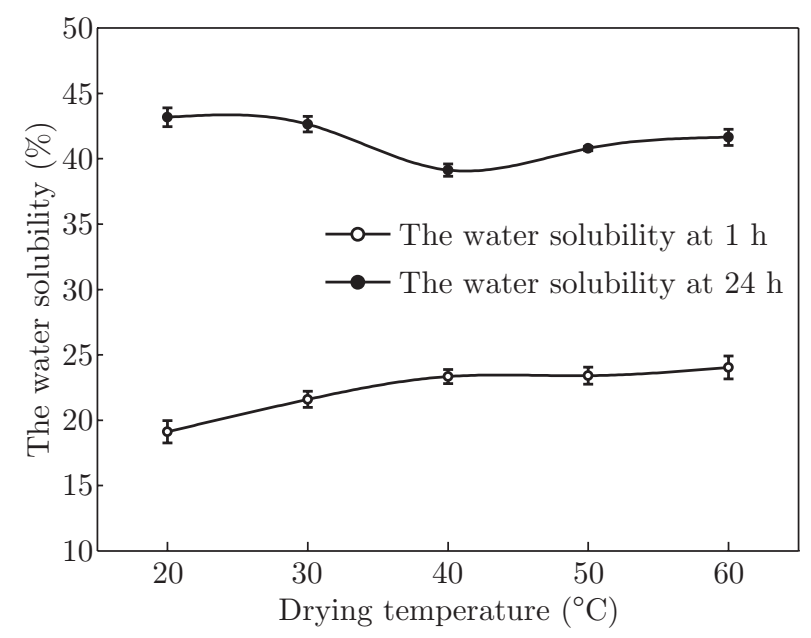

Fig. 6: The effect of drying temperature on the water solubility of sericin membranes (Tyrosinase 1000 $\mathrm{U} / \mathrm{g}$, reaction time $120 \mathrm{~min}$, reaction temperature $45^{\circ} \mathrm{C}$ )

\subsection{The Effect of Glycerol on the Water Solubility of Sericin Mem- branes}

Fig. 7 shows the effect of glycerol on the water solubility of sericin membranes. The water solubility of sericin membranes decreased with the addition of glycerol in catalytic reaction of sericin and tyrosinase at $1 \mathrm{~h}$.

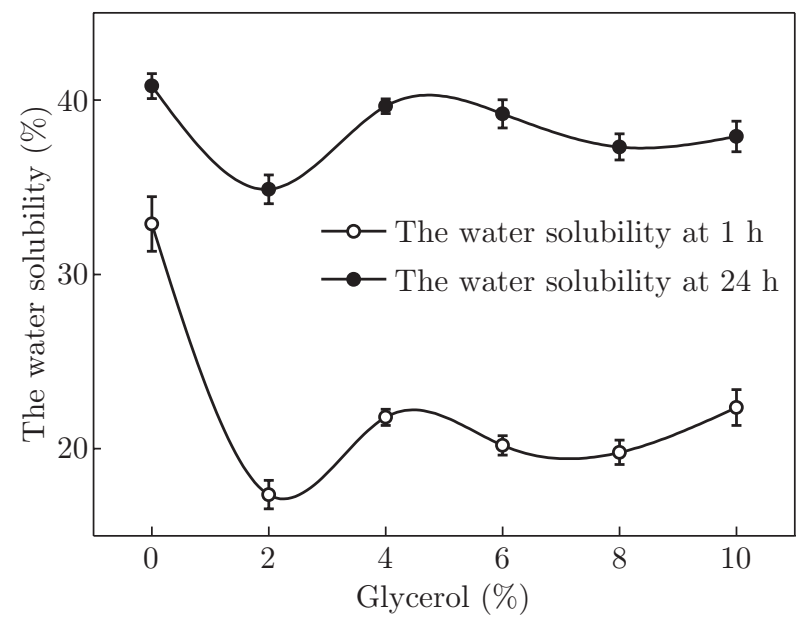

Fig. 7: The effect of glycerol on the water solubility of sericin membranes (Tyrosinase $1000 \mathrm{U} / \mathrm{g}$, reaction time $120 \mathrm{~min}$, reaction temperature $45^{\circ} \mathrm{C}$, drying temperature $40^{\circ} \mathrm{C}$ )

The sericin membranes obtained after enzymatic reaction were thin and brittle. It was difficult to achieve a complete membrane. Hydrogen bonds formed between the $-\mathrm{OH}$ in glycerol molecules and sericin molecules, which could promote the cross-linking. The mutual slippage of protein macromolecular chains caused the deformation of the membranes in macroscopic. The energy absorbed during the deformation made the membranes toughness.

The small glycerol molecules were attached to the macromolecular chains of sericin. The polar group of glycerol and the sericin macromolecules interacted and the swelling of the sericin took place, which is due to shielding the non-polar part of the macromolecules by the polar group 
of the glycerol portion. As a result, the amount of hydroxyl in original system decreased. This reduced the deposition of the glycerol absorbent and gradually improved the water solubility of sericin membranes. The barrier effect of the presence of macromolecules would be too strong to reduce the forces between the sericin molecules where the amount of glycerol was excessive. Additionally, part of glycerol might be present in sericin membranes as free state, which in turn increased the rate of moisture absorption and the water solubility of membranes was improved. The optimal dosage of glycerol was found $2 \%$.

\subsection{Fourier Transform Infrared (FT-IR) Analysis of Sericin Mem- branes}

Amide I, amide II and amide III three structures exist in the infrared spectrum of sericin. The characteristic absorption peaks were about 1647 or 1535 or $1246 \mathrm{~cm}^{-1}$.

Fig. 8 shows FT-IR spectra of pure sericin membrane and cross-linking sericin membrane. There are a little difference between them. Both of the pure sericin and cross-linking sericin membranes show an absorption peak at 1535 or $1246 \mathrm{~cm}^{-1}$ which proved the existence of amide II and amide III, respectively. Moreover, the another absorption peak of pure sericin membrane appears at 1642 $\mathrm{cm}^{-1}$, indicated that the structure of amide I exists. However, the absorption peak of crosslinking membrane cracking into three low peak, indicating that the structure of amide I has changed to some extent.

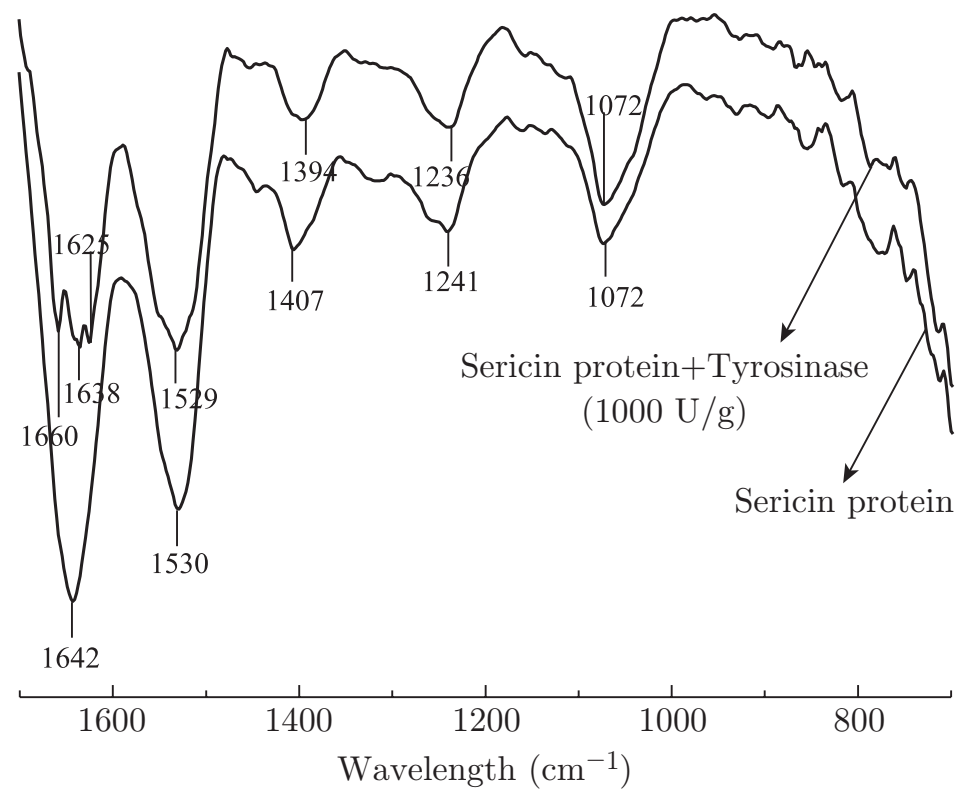

Fig. 8: The FT-IR of sericin membranes

\subsection{The Analysis of XPS}

The percentage of $\mathrm{C}, \mathrm{O}, \mathrm{N}$ on the surface of sericin membranes was tested by X-ray photoelectron spectroscopy. Fig. 9 shows the X-ray absorption intensity of three elements. It can be seen that the absorption intensity of $\mathrm{O}$ was the highest. Compared with Fig. 9 (a), it is obvious that the $\mathrm{O}$ absorption intensity of the crosslinking membranes was higher the pure membranes. 


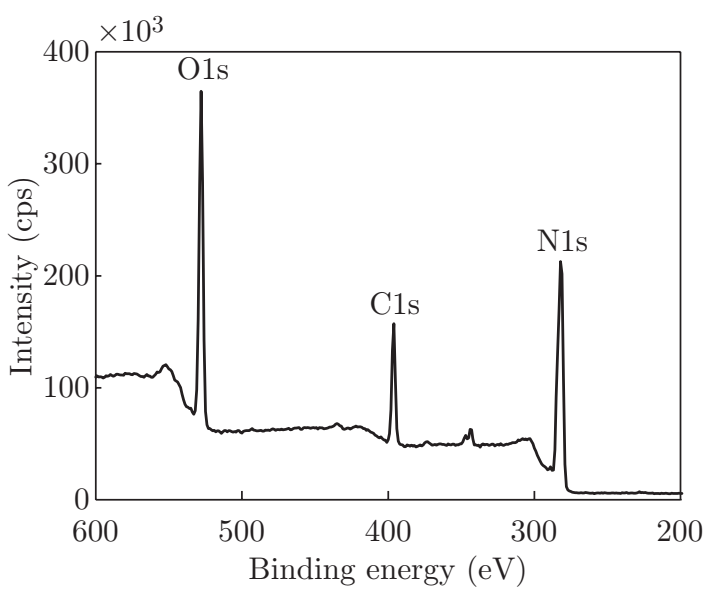

(a) Pure sericin membrane

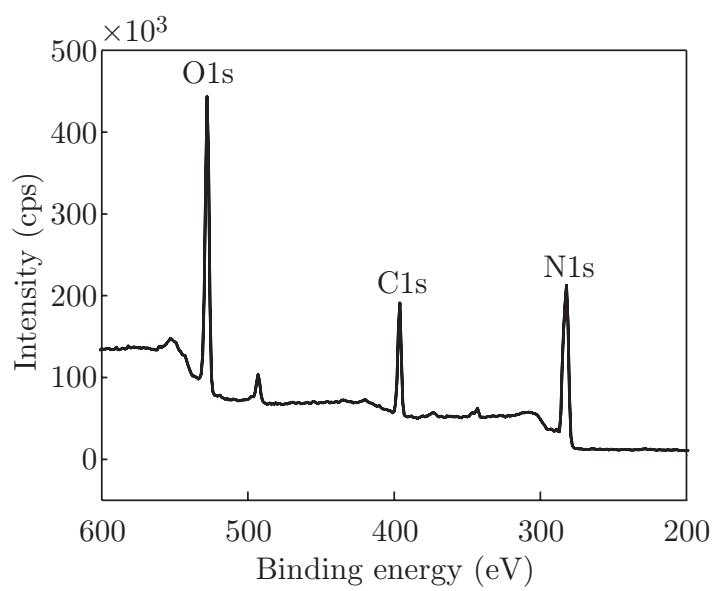

(b) Tyrosinase crosslinked membrane $(1000 \mathrm{U} / \mathrm{g})$

Fig. 9: The analysis of XPS

Table 1 shows the atomic mass percentage of three elements on the surface of sericin membranes. The $\mathrm{C} / \mathrm{O}$ ratio of the crosslinking membranes was 2.09 and the pure membranes was 2.79 . $\mathrm{O}$ atom content increased in crosslinked sericin membrane, indicating the enzymatic reaction occurred and more phenol hydroxyl groups were oxidized into diphenols and benzoquinones.

Table 1: The atomic mass percentage of $\mathrm{C}, \mathrm{O}, \mathrm{N}$ on the surface of sericin membranes

\begin{tabular}{cccccc}
\hline Element & $\mathrm{C}$ & $\mathrm{O}$ & $\mathrm{N}$ & $\mathrm{C} / \mathrm{O}$ & $\mathrm{C} / \mathrm{N}$ \\
\hline Pure sericin membranes & 63.82 & 22.87 & 13.30 & 2.79 & 4.80 \\
Crosslinking sericin membranes & 57.20 & 27.35 & 15.45 & 2.09 & 3.70 \\
\hline
\end{tabular}

\section{Conclusion}

The optimal sericin membrane fabrication condition was determined as follows: the dosage of tyrosinase $1000 \mathrm{U} / \mathrm{g}$, reaction temperature $45^{\circ} \mathrm{C}$, time $90 \mathrm{~min}, 2 \%$ glycerol and drying temperature $45{ }^{\circ} \mathrm{C}$. The water solubility of sericin membrane was reduced under above conditions.

The result of infrared spectrometry indicates that the structure of amide I was changed in crosslinked sericin membrane. The XPS results showed the O atom content was increased in crosslinked sericin membrane by tyrosinase. This work provides the foundation for tyrosinase enzymatic crosslinking sericin membranes, which has potential application in biomaterials field.

\section{References}

[1] O. Orliac, A. Rouilly, F. Silvestre, L. Rigal, Effects of various plasticizers on the mechanical properties, water resistance and aging of thermo-moulded films made from sunflower proteins, Ind. Crop. Prod., 18, 2003, 91-100

[2] M. Q. Li, C. Li, Z. L. Ai, Z. M. Liu, W. G. Suo, The effect of dry temperature on the properties of edible wheat gluten films, Science and Technology of Food Industry, 11, 2004, 78-80, 99 
[3] O. Akturk, A. Tezcaner, H. Bilgili, M. S. Deveci, M. R. Gecit, D. Keskin, Evaluation of sericin/ collagen membranes as prospective wound dressing biomaterial, J. Biosci. Bioeng., 112, 2011, 279-288

[4] W. J. Lin, H. Z. Liu, L. Liu, Effect of different sugars grafting on physical properties of peanut protein film, Trans. CSAE, 30, 2014, 261-267

[5] J. H. Wu, Z. Wang, S. Y. Xu, Enzymatic production of bioactive peptides from sericin recovered from silk industry wastewater, Process. Biochem., 43, 2008, 480-487

[6] R. J. Xie, M. Z. Li, S. Z. Lu, H. J. Sheng, Preparation of flexible sericin film, Silk, 9, 2005, 20-22

[7] S. Wang, Y. Goto, Y. Ohkoshi, M. Nagura, Structures and physical properties of poly (vinyl alcohol)/sericin blend hydrogel membranes, Silk of Jap, 4, 1998, 295-302

[8] A. Anghileri, R. Lantto, K. Kruus, C. Arosio, G. Freddi, Tyrosinase catalyzed grafting of sericin peptides onto chitosan and production of protein-polysaccharide bioconjugates, J. Biotechnol., 127, 2007, 508-519

[9] S. Sampaio, P. Taddei, P. Monti, J. Buchert, G. Freddi, Enzymatic grafting of chitosan onto Bombyx mori silk fibroin: Kinetic and IR vibrational studies, Biotechnol., 116, 2005, 21-33

[10] Y. Matoba, T. Kumagai, A. Yamamoto, H. Yoshitsu, M. Sugiyama, Crystallographic evidence the dinuclear copper center of tyrosinase is flexible during catalysis, J. Biol. Chem., 281, 2006, 8981-8990

[11] B. Monisha, Q. Luo, H. Corke, Time-dependent changes in dough color in hexaploid wheat landraces differing inpolyphenol oxidase activity, J. Agr. Food Chem., 47, 1999, 3579-3585

[12] K. Shinya, H. Akira, N. Shun, Y. Yuka, F. Taketoshi, T. Kei, M. Shigeru, H. Tadashi, S. Tamio, M. Kayoko, Depigmentation caused by application of the active brightening material, rhododendrol, is related to tyrosinase activity at a certain threshold, J. Dermatol. Sci., 76, 2014, 16-24

[13] S. Jus, V. Kokol, G. Guebitz, Tyrosinase-catalysed coupling of functional molecules onto protein fibers, Enzyme. Microb. Tech., 42, 2008, 535-542

[14] G. Freddi, A. Anghileri, S. Sampaio, J. Buchert, P. Monti, P. Taddei, Tyrosinase-catalyzed modification of Bombyx mori silk fibroin: Grafting of chitosan under heterogeneous reaction conditions, J. Biotechnol., 125, 2006, 281-294

[15] M. Michael Cox, David Lee Nelson, Lehninger Principles of Biochemistry, New York: W. H., 2008 